\title{
Responsiveness to People's Non-medical Expectations (Comparing Educational and Non-Educational Centers)
}

\author{
somayeh noori Hekmat ${ }^{1}$, sajad khosravi ${ }^{2}$, roghayeh ershad sarabi ${ }^{1}$, saeedeh bastan ${ }^{2}$, and \\ mohammadreza rajabalipour ${ }^{3}$ \\ ${ }^{1}$ Kerman University of Medical Sciences \\ ${ }^{2}$ Affiliation not available \\ ${ }^{3}$ Bam University of Medical Sciences
}

May 15, 2020

\begin{abstract}
objective: The health system should be responsive to the needs of the clients, and the regular monitoring of accountability system will help to identify the weaknesses and, by eliminating these deficiencies the motivation for providing services to clients will also increase. Therefore, this study was conducted to assess the status of responsiveness to people's non-medical expectations in educational and non-educational centers of Iran. Methods: This cross-sectional study was conducted on 112 patients who referred to the hospitals and medical centers. Sampling was conducted randomly on all clients during a 15-day period. The data were collected by a questionnaire that was standardized in similar studies. Finally, data were analyzed by SPSS23 and the scores of responsiveness dimension were measured. Results: Although the scores of many responsiveness dimensions in non-educational centers were higher than educational centers, but ultimately there was no significant difference between the scores of different responsiveness dimensions in educational and non-educational centers. Conclusion: Educational and public health centers need more attention compared to non-educational centers to improve responsiveness to people's nonmedical expectations. According to the obtained results, the priority of the actions is focused on providing the required human resources.
\end{abstract}

\section{Introduction}

Hospitals and health centers are the key institutions to provide the community health and most of their services determine the death or survival of individuals., ${ }^{1,2}$ Therefore, the quality of services, providing the satisfaction of clients and observance of professional ethics in these centers is inevitable, ${ }^{3,4}$ because the health system should meet the needs of clients. The World Health Organization (WHO) has determined the health system responsiveness as the most important component of the policy-makers' and health system managers' discussion. $^{5}$ In fact, the responsiveness system is focused on the rational expectations of individuals in non-medical aspects of health services. ${ }^{6}$

In order to evaluate the health system responsiveness, a framework is developed by WHO that health systems responsiveness is defined as experiences of health service users along the eight dimensions: dignity, autonomy, confidentiality, prompt attention, access to social support networks during care, communication, quality of basic amenities and choice of care provider. ${ }^{7}$ WHO also developed detailed survey tools and guidelines which have been used and adapted in multiple countries. ${ }^{8}$

According to the report of the WHO in 2015, although Iran has been well-developed among the countries of the world in the responsiveness, but still is not in a good position, and this rank represents a gap between the current qualities and expected. ${ }^{9}$ The results of studies also indicate this status . ${ }^{7,8,10,11}$ This can gradually lead to dissatisfaction, disconnection of people and a reduction of their participation in the health system, 
which ultimately will reduce the efficiency and effectiveness of the health system.${ }^{12}$ Of course, there is little difference between the services of the public and private sector. ${ }^{13}$

There are several strategies to improve the responsiveness in the health sector, but the first step is to assess the status of the responsiveness system accurately and then identify the correct intervention point to eliminate these deficiencies. ${ }^{14,15}$ Regular monitoring of the responsiveness system helps to better identification of weaknesses and, by eliminating these deficiencies, the motivation will be more to provide services for clients. ${ }^{16}$ Therefore, the present study is conducted with the aim of assessing the rate of responsiveness to people's non-medical expectations in educational and non-educational centers in Iran.

\section{Methods}

\section{Sampling and study type}

This cross-sectional study conducted on 112 patients who referred to the hospitals and health centers of Bam, Iran. Our sample study selected by quota sampling, first we divided all hospitals in two group of educational and non-educational. We selected $64 \%$ of samples from educational and $36 \%$ from non-educational hospitals proportional to total number of beds in each group. then required samples selected by random sampling.

\section{Data collection}

In this study, data were collected by WHO responsiveness questionnaire. The validity of the translated version of the questionnaire was confirmed by previous study. ${ }^{17}$ The questionnaire was consisted of 2 section. The first section included the questions related to patient for example age, sex and etc. The second section included 30 questions in 8 dimensions including dignity, autonomy, confidentiality, prompt attention, access to social support networks during care, communication, quality of basic amenities and choice of care provider.

\section{Data analysis}

The collected data were analyzed by SPSS, Version 23 software at descriptive and analytical levels. At the descriptive level, we used frequency, percent, mean and standard deviation. In order to achieve the study objectives, t-test, chi-square, ANOVA and Pearson correlation coefficient were used.

\section{Results}

The mean age of participants of the study was 34.35 with a standard deviation of 13.79 years. More than half of the participants of the study were women, and most of them had high school education and diploma. Likewise, the occupation of the most of male participants was mentioned self-employed, while women were often housewives. The most reason for referring to the health centers was accidents (Table 1).

The results of the study indicated that although in most dimensions such as the quality of physical facilities, privacy of patients' information, selection of care provider and communication, the score of non-educational centers was higher than educational centers, but there was not any significant difference in none of the areas of accountability between educational and non-educational centers (Table 2 and Chart 1).

The results of the correlation analysis between different areas of accountability indicated that all areas are strongly and directly related to each other; meaning that by the increase and promotion of one area, the other areas also increase equally. Only, there was no meaningful relation between independence and autonomy and the access to support networks (Table 3).

\section{Discussion}

This study was conducted to evaluate the responsiveness to people's non-medical expectations in educational and non-educational centers according to the opinion of patients. Based on the obtained results of the present study, the responsiveness score of the studied health centers was $72.22 \%$, indicating that on the opinion of patients, the health centers of Bam responded to the patient's non-medical expectations more than average and at the optimal level. These findings are consistent with the results of similar studies. ${ }^{18,19,20}$ The study by Mohseni et al. reported the responsiveness level of educational hospitals as medium to high. ${ }^{18}$ Likewise, 
in the study by Yusefi, the responsiveness of hospitals was moderate to high. ${ }^{19}$ Of course, paying attention to satisfaction of clients in the scope of medical and non- medical expectations is one of the main indexes of evaluation and reliability of hospitals, which has led the officials of health centers and hospitals to pay special attention to this area, which usually keeps the level of overall satisfaction as moderate. ${ }^{21}$ Likewise, the development of social networks and increased awareness about the rights of patients have made health centers and hospitals to be more exposed to general monitoring and evaluation, and this factor, along with others, will cause environmental enhancement and increase the responsiveness of health care personnel. ${ }^{22,23}$

In this study, the responsiveness level of non-educational and private centers was slightly higher than public and educational centers, because for non- educational and private health care centers, satisfaction of clients is considered as one of the most important issues and has great impact on accreditation, income generation and competition with other hospitals. ${ }^{24,25,26}$ Likewise, individuals expect more from the private sector to provide services with better quality than the public sector. ${ }^{24,27}$

In this study, "honor and human dignity" had the highest score. The score of non-educational and private centers in this area was higher than educational and public health centers. In the study by Gohari, the responsiveness was in good status, and preserving human dignity had a good score. ${ }^{28}$ In a similar study by Pletzer in Africa, respecting dignity had the best score in terms of responsiveness dimensions. ${ }^{29}$ In noneducational hospitals, in comparison to public and educational hospitals, the low number of clients and the reduction of work pressure on health care personnel provides more time for treatment and better focus on the provision of health care and non-medical services, which ultimately leads to the improvement of the honor status of patients. ${ }^{30,31}$ The level of public awareness about the patients' rights and the code of ethics is another significant point in the area of human dignity and honor. ${ }^{32}$ Patients of public health centers in small cities with low facilities like Bam are often from neighborhood villages and towns with low educational level and are unable to cover heavy expenses in non-educational and private sectors. ${ }^{18,24}$ Therefore, they do not have enough knowledge about ideal conditions and are satisfied with the minimum requirements. Therefore, sometimes they regard the present situation as ideal and do not have any objection. ${ }^{20}$ Of course, recent attentions to public hospitals has also been a major factor to strengthening this area and achieving greater satisfaction. ${ }^{33}$

The selection of service provider has the lowest score in the present study. In the study by Gohari and Rashidian, the lowest responsiveness was also for the selection of the service provider. ${ }^{24,28}$ On the contrary to this result, in the study of the ten OECD countries, the best responsiveness operation was observed in the area of the service provider, which is not consistent with the present study. ${ }^{32}$ This indicates the impact of the economic situation on this dimension. In fact, this dimension is directly related to the index number of service providers and nurses to the population. ${ }^{34}$ The low score of this dimension indicates the limitations and shortage of human resource in health centers of Bam, since the number of nurses and personnel providing services to the population in these centers is lower than the national average, so patients have no option to choose, and sometimes a nurse has the direct responsibility for responding to several patients. ${ }^{35}$ The score of this dimension is important for health officials and policymakers to provide the required human resources and assess the future needs.

\section{Conclusion}

The rate of responsiveness to people's non-medical expectations in different educational and non-educational medical centers of Bam was about $65 \%$ and more than average. Although the total score of responsiveness in non-educational centers was higher than that of educational centers, but no significant difference was observed between them. However, paying more attention and equipping the public and educational centers will help to enhance responsiveness. According to the obtained results, providing the required human resource is in priority.

\section{Acknowledgement}

In this study, we express our gratitude to the Deputy of Research and Technology of Medical Sciences of Bam University and all the staff of the aimed medical centers who sincerely and responsibly cooperated 
in completing the data collection process. Likewise, we are grateful to the Public Health Department of the Medical Sciences department of Bam University for the issuance of the letter of introduction for the cooperation of students.

\section{References}

1. Danaee fard H, Rajabzadeh A, Darvishi A. The role of Islamic-ethical competence in increasing public hospitals accountability \%J Journal of Medical Ethics and History of Medicine. 2010;3(4):57-70.

2. Arefi M, Talaei NJJoPS. Patient satisfaction in Baharloo Hospital in 2008. 2010;4(2):97-103.

3. Farsi nm, bazmi s, teimouri b, resane s. Comparison of patient satisfaction from patients'right charter in public and private hospitals in tehran. 2012.

4. Javadi $\mathrm{m}$, yaghoobi $\mathrm{m}$, raiesi a, mandegar ha, ayoobian a. A study of non-medical aspects of health services provided to patients in selected hospitals of isfahan: responsiveness. 2011.

5. Küsters R, Truderung T, Vogt A, editors. Accountability: definition and relationship to verifiability. Proceedings of the 17th ACM conference on Computer and communications security; 2010: ACM.

6. Wachter RMJBQS. Personal accountability in healthcare: searching for the right balance. BMJ Qual Saf. 2013;22(2):176-80.

7. Rahmanian E, Arab M, Hosseini SM, Mardani M. The Relationship between Organizational Justice and Responsibility in Hospitals of Tehran University of Medical Sciences \% J Iran Occupational Health Journal. Iran Occupational Health Journal. 2017;14(3):152-63.

8. Hedayati SP, Faraji UA, Mohabati F, Hamedi S, Emadi V, Sharifi TJMEJ. Relationship between organizational justice and employees' productivity in hospitals of Zabol city; 2010. Medical Ethics Journal. 2016;5(17):105-18.

9. Faseleh-Jahromi M, Moattari M, Peyrovi HJNE. Iranian nurses' perceptions of social responsibility: A qualitative study. Nursing Ethics. 2014;21(3):289-98.

10. Gharaee H, Bahrami M-A, Rejalian F, Atashbahar O, Homayoun A, Ataollahi F, et al. The relationship of organizational perceived justice and social responsibility in Yazd hospitals, Iran. Journal of Management and Medical Informatics School. 2013;1(1):26-37.

11. Tavakoli AM, Rajabi MJJoh, development. The Relationship between Organizational Justice Perception and Job Satisfaction: a study on employees of Kerman University of Medical Sciences. Journal of health and development. 2013;2(1):22-32.

12. Nader K, Lida S, Somaye Y, Ebrahim JP, Taha N, Narges R, et al. The Relationship Between Organizational Health and Organizational Citizenship Behavior in Hospitals Affiliated to Tehran University of Medical Sciences In 2010. Payavard Salamat. 2013;6(6).

13. Casalino LP, Erb N, Joshi MS, Shortell SMJJohp, policy, law. Accountable care organizations and population health organizations. Journal of health politics, policy and law. 2015;40(4):821-37.

14. Brinkerhoff DWJHp, planning. Accountability and health systems: toward conceptual clarity and policy relevance. Health policy and planning. 2004;19(6):371-9.

15. Axon RN, Williams MVJJ. Hospital readmission as an accountability measure. Jama. 2011;305(5):5045.

16. Fisher ES, Shortell SMJJ. Accountable care organizations: accountable for what, to whom, and how. Jama. 2010;304(15):1715-6.

17. Javadi, M., Karimi, S., Raiesi, A., Yaghoubi, M., \& Kaveh, K. (2011). Comparison of patients' and nurses' View-points about responsiveness among a sample from public and private hospitals of Isfahan. Iran J Nurs Midwifery Res., 16 (4), 273-277.

18. Seyedin sh, mohseni m, Hossaini af, Gharasi Manshadi M, asadi h. Situation Analysis of Performance Accountability in Teaching Hospitals Affiliated to Tehran University of Medical Sciences \%J Hospital. 2015;14(2):95-100.

19. Yousefi M, Ebrahimipour H, Banikazemi HJJoPS, Rehabilitation. Responsiveness of the Health System in Outpatient Services in low- and high-income Areas of Mashhad. 2016;5(2):58-66.

20. Manuel J, Crowe MJIjomhn. Clinical responsibility, accountability, and risk aversion in mental health nursing: A descriptive, qualitative study. 2014;23(4):336-43. 
21. Bahadori M, Ravangard R, Alimohammadzadeh KJIjoph. The accreditation of hospitals in iran. 2015;44(2):295-6.

22. Kim J, Hardin AJJoHM, Management. The impact of virtual worlds on word-of-mouth: Improving social networking and servicescape in the hospitality industry. 2010;19(7):735-53.

23. Hajli MNJIJoMR. A study of the impact of social media on consumers. 2014;56(3):387-404.

24. Zarei A, Arab M, Froushani AR, Rashidian A, Tabatabaei SMGJBhsr. Service quality of private hospitals: The Iranian Patients' perspective. 2012;12(1):31.

25. Rashidian A, Kavosi Z, Majdzadeh R, Pourreza A, Pourmalek F, Arab M, et al. Assessing health system responsiveness: a household survey in 17th district of tehran. 2011;13(5):302.

26. Ebrahimipour H, Najjar AV, Jahani AK, Pourtaleb A, Javadi M, Rezazadeh A, et al. Health system responsiveness: a case study of general hospitals in Iran. 2013;1(1):85.

27. Arab M, Tabatabaei SG, Rashidian A, Forushani AR, Zarei EJIjoph. The effect of service quality on patient loyalty: a study of private hospitals in Tehran, Iran. 2012;41(9):71.

28. Gohari M, Tabibi SJ, Nasiripour A, Mahboubi M. Seven Dimensions of Accountability in Iran's Teaching Hospitals: A National Study \%J Payavard Salamat. 2012;6(4):255-64.

29. Peltzer K, Phaswana-Mafuya NJGha. Patient experiences and health system responsiveness among older adults in South Africa. 2012;5(1):18545.

30. Nasiripour AA, Tabibi SJ, Gohari MR, Mahboubi M. Dimensions of Accountability from The Perspective of Educational Hospital Staff \%J Journal of Rafsanjan University of Medical Sciences. 2013;12(5):377-88.

31. Vejdani M, Godarzeyan M, Rahimi Z, Saffari SE, Vejdani M, Fouji S, et al. Responsiveness in Health Service: Patients Experience in Hospital of Sabzevar \%J Journal of Sabzevar University of Medical Sciences. 2016;23(4):662-71.

32. Valentine N, Darby C, Bonsel GJJSs, medicine. Which aspects of non-clinical quality of care are most important? Results from WHO's general population surveys of "health systems responsiveness" in 41 countries. 2008;66(9):1939-50.

33. Haghdoost A, Hashemi H, Noori Hekmat S, Haji Aghajani M, Janbabaee G, Maher A, et al. The Geographical Distribution of Hospital Beds in Iran in 2016 and the Estimation of 2026 \%J Iranian Journal of Epidemiology. 2018;13(0):1-13.

34. Foxall MJ, Zimmerman L, Standley R, Bene Captain BJJoAN. A comparison of frequency and sources of nursing job stress perceived by intensive care, hospice and medical-surgical nurses. 1990;15(5):577-84.

35. Haji Aghajani M, Haghdoost A, Noori Hekmat S, Janbabaee G, Maher A, Javadi A, et al. Geographical Distribution of Different Groups of Medical Staff in Iran in 2016 and the Estimates for 2026 \%J Iranian Journal of Epidemiology. 2018;13(0):71-84.

\section{Hosted file}

Table and charts 001.docx available at https://authorea.com/users/322272/articles/451314responsiveness-to-people-s-non-medical-expectations-comparing-educational-and-noneducational-centers 